Journal of the Electrochemical Society, Vol. 150, No. 2, 2003, pp. B83-B91.

ISSN: 0013-4651

DOI: $10.1149 / 1.1537755$

http://www.electrochem.org/

http://www.ecsdl.org/getpdf/servlet/GetPDFServlet?filetype=pdf\&id=JESOAN000150000002000B83000001\&idty

pe $=$ cvips\&prog $=$ normal

(C) The Electrochemical Society, Inc. 2003. All rights reserved. Except as provided under U.S. copyright law, this work may not be reproduced, resold, distributed, or modified without the express permission of The Electrochemical Society (ECS). The archival version of this work was published in Journal of the Electrochemical Society, Vol. 150, No. 2, 2003, pp. B83-B91.

\title{
Storage and Release of Soluble Hexavalent Chromium from Chromate Conversion Coatings on Al Alloys
}

\section{Kinetics of Release}

\section{E. Akiyama, ${ }^{\text {a,d }}$ A. J. Markworth, ${ }^{\text {a }}$ J. K. McCoy, ${ }^{\text {c }}$ G. S. Frankel, ${ }^{\text {a, } * \text { L. Xia, }}{ }^{\text {and R. L. }}$ McCreery $^{b}, *$}

${ }^{a}$ Fontana Corrosion Center, Department of Materials Science and Engineering, and ${ }^{b}$ Department of Chemistry, The Ohio State University, Columbus, Ohio ${ }^{c}$ Framatome ANP, Lynchburg, Virginia

* Electrochemical Society Active Member.

${ }^{\mathrm{d}}$ Present address: National Institute for Materials Science, Tsukuba, 305-0047 Japan.

The release of chromate ions from chromate conversion coatings (CCCs) on Al alloys was studied, and the effect of aging of CCCs on the chromate release kinetics was investigated. Chromate release from CCCs into aqueous solutions was monitored by measuring the change in the chromate concentration in solution using UVvisible spectroscopy. Heat-treatment of the CCC greatly reduced the chromate release rate. The chromate release rate also decreased with increasing aging time at room temperature. A diffusion-control model was proposed based on the notion that the CCC in an aqueous solution is a porous, two-phase structure consisting of a solid phase with adsorbed $\mathrm{Cr}(\mathrm{VI})$ species that is in local Langmuir-type equilibrium with an interpenetrating solution phase. This model results in a concentration gradient of soluble $\mathrm{Cr}(\mathrm{VI})$ in the solution phase of the $\mathrm{CCC}$ as chromate is released. The concentration and diffusion coefficients of soluble $\mathrm{Cr}(\mathrm{VI})$ in $\mathrm{CCC}$ were estimated. The estimated diffusion coefficient tended to decrease with aging time, suggesting that the CCC is modified with aging time.

For aircraft coating technology, understanding the mechanism of aluminum corrosion and the effect of chromates on corrosion inhibition is important. Chromate conversion coatings (CCCs) are commonly used on aluminum alloy surfaces to improve the corrosion resistance and to establish an adhesive base for organic coatings. Chromate ions have increased the pitting potential of aluminum alloys in chloride media and reduced the rates of pit nucleation and growth if present in a high enough concentration. ${ }^{1,2}$ One of the important aspects of CCCs is the dynamic repair of newly created breaks on coated metals, which is called self-healing. For example, a CCC-treated Al alloy sample with a scribe mark through the coating to the metal exhibits minimal corrosion in salt-spray testing.

Zhao et al. demonstrated the migration of chromates from a CCC to an uncoated metal surface by detecting $\mathrm{Cr}$ on the surface of an initially untreated AA2024-T3 sample immersed in chloride solution in close proximity to a CCC-treated sample. ${ }^{3}$ The release of Cr(VI) from CCCs was further studied using UV-Visible spectroscopic analysis of solutions exposed to samples with CCCs. ${ }^{4}$ The observations were consistent with a release mechanism similar to Langmuir 
adsorption and desorption of $\mathrm{Cr}(\mathrm{VI})$ from a porous, insoluble $\mathrm{Cr}(\mathrm{III})$ matrix. To fully understand the inhibition behavior of CCCs, one must fully understand the chromate release phenomenon. In the present study, the release of $\mathrm{Cr}(\mathrm{VI})$ from $\mathrm{CCCs}$ is examined for samples under a range of conditions, and a model describing the release kinetics is developed.

\section{Experimental}

CCCs were prepared on aluminum alloys AA1100 and AA2024-T3 by immersion in Alodine 1200S (Henkel Surface Technologies) solutions at room temperature. The Alodine bath consisted of $9.0 \mathrm{gL}^{-1}$ of a mixture reported to be $50-60 \% \mathrm{CrO}_{3}, 20-30 \% \mathrm{KBF}_{4}, 10-15 \%$ $\mathrm{K}_{3} \mathrm{Fe}(\mathrm{CN})_{6}, 5-10 \% \mathrm{~K}_{2} \mathrm{ZrF}_{6}$, and $5-10 \% \mathrm{NaF}$ by weight, which is approximately $0.065 \mathrm{M}$ in $\mathrm{Cr}$. The $\mathrm{pH}$ of the bath was adjusted to 1.5 by the addition of nitric acid. The AA1100 samples $(3 \mathrm{~cm}$ $\times 8.35 \mathrm{~cm} \times 50 \mu \mathrm{m}$ ) were given an acidic pretreatment using a triply diluted, commercially available detergent, Alumiprep 33 (Henkel Surface Technologies), and the AA2024-T3 samples were prepared by polishing to 1200 grit paper in water, rinsing with deionized (DI) water and degreasing in alcohol before the Alodine treatment. Most samples were treated in the Alodine bath for $5 \mathrm{~min}$. After Alodine treatment, the samples were rinsed by dipping in DI water, and aged in air at room temperature or at 50,100 , or $200^{\circ} \mathrm{C}$. After a certain period of aging time, chromate release was determined during immersion in stagnant DI water or $0.1 \mathrm{M} \mathrm{NaCl}$ solution at room temperature in glass beakers or glass vials. To avoid evaporation of water, the beakers were covered with vinyl sheets.

The concentrations of released $\mathrm{Cr}$ ions in solutions were periodically measured by UVvisible spectroscopy using a home-built system controlled by a LabVIEW program. A cuvette of $10 \mathrm{~mm}$ path-length containing sample or reference solution was placed in the path of monochromated incident light. The intensity of the transmitted light was measured by a power meter, and the absorption was determined as a function of the wavelength of the incident light. After the measurements, the solution in the cuvette was replaced in the test beaker. Quantitative determination of $\mathrm{Cr}(\mathrm{VI})$ concentration was calculated from UV absorption at the isosbestic point of $340 \mathrm{~nm}$, where the absorption is independent of $\mathrm{pH}$ and is linearly related to the concentration of total $\mathrm{Cr}(\mathrm{VI}) .^{4,6,7}$ The linear calibration relation of $\mathrm{Cr}(\mathrm{VI})$ concentration to absorption measured at $340 \mathrm{~nm}$ can be written as $[\mathrm{Cr}(\mathrm{VI})]=\left(\mathrm{Abs}_{340} 0.00157\right) / 1062$. An absorption of 1 is almost equal to $1 \mathrm{mM}$ of total $\mathrm{Cr}(\mathrm{VI})$; hereafter, we express the concentration of total $\mathrm{Cr}(\mathrm{VI})$ by absorption.

\section{Results and Discussion}

Effect of heat-treatment.-The $0.1 \mathrm{M} \mathrm{NaCl}$ solution in contact with a CCC-treated AA1100 sample aged for $2 \mathrm{~h}$ at room temperature tended to show an increase in $\mathrm{Cr}(\mathrm{VI})$ concentration with time, approaching a constant value, as evidenced by an increase in the absorption at $340 \mathrm{~nm}$ (see Fig. 1). The sample heat-treated at $50^{\circ} \mathrm{C}$ for $2 \mathrm{~h}$ showed remarkably less chromate release than the sample aged at room temperature. CCC samples heat-treated at 100 or $200^{\circ} \mathrm{C}$ did not release detectable amounts of chromates. The CCC sample aged at $200^{\circ} \mathrm{C}$ lost the brownish golden color characteristic of CCCs as the color of the sample turned to metallic gray. Clearly, heat-treatment suppressed the release of chromates from the CCCs.

Effect of aging and ratio of surface area to solution volume $(S / V)$. - Figure 2 shows the 
effect of room-temperature aging on chromate release from CCC-treated AA1100. Note that all samples described hereafter were aged at room temperature. In general, the concentration of $\mathrm{Cr}(\mathrm{VI})$ in solution increased with immersion time and then reached an almost constant level of

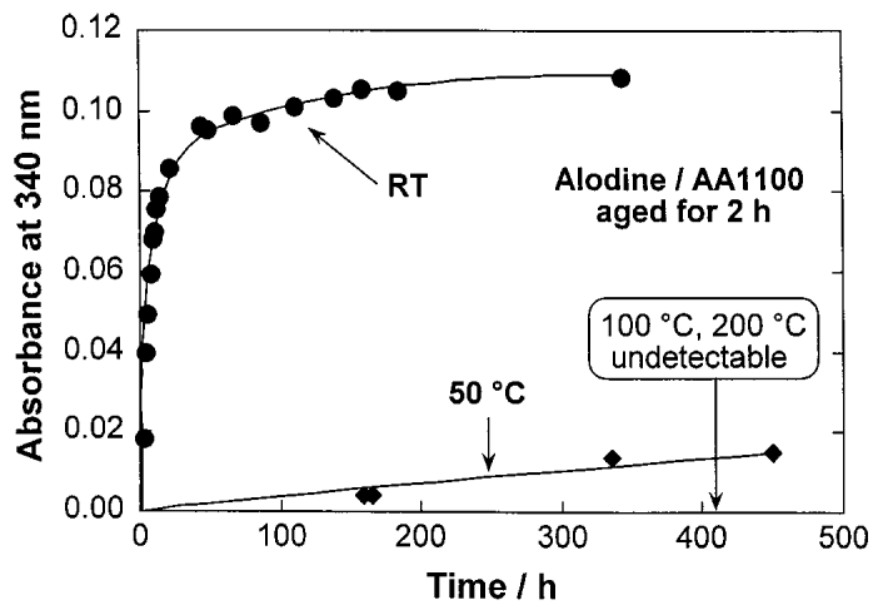

Figure 1. Comparison of chromate release curves of CCCs on AA1100 aged at room temperature or at 50, 100, or $200^{\circ} \mathrm{C}$ for $2 \mathrm{~h}$. The concentrations of chromate released from CCC samples aged at 100 and $200^{\circ} \mathrm{C}$ were undetectable. An absorption of 1 is almost equal to $1 \mathrm{mM}$ of [Cr(VI)]. The surface area of each CCC sample was 50 $\mathrm{cm}^{3}$, and the volume of DI water was $30 \mathrm{~cm}^{3}$.

concentration. The release rate of chromates from CCC decreased with increasing roomtemperature aging time. The release rate in $0.1 \mathrm{M} \mathrm{NaCl}$ solution was higher than that in $\mathrm{DI}$ water. The samples polished slightly by $\mathrm{SiC}$ paper before immersion in water did not behave significantly differently than the unpolished samples, which indicates that aging did not only affect the very surface of the CCCs. For the samples in this figure, the surface area and solution volume were $50 \mathrm{~cm}^{2}$ and $30 \mathrm{~mL}$, respectively, so that $S / V$ was $1.67 \mathrm{~cm}^{-1}$.

The release of $\mathrm{Cr}(\mathrm{VI})$ from CCCs on AA1100 aged for $2 \mathrm{~h}$ for different $S / V$ ratios is compared in Fig. 3. The Cr(VI) concentration increased with $S / V$ ratio. The steady-state value of $\mathrm{Cr}(\mathrm{VI})$ concentration for $S / V=5$ was about three times the value for $S / V=1.67$, so it varied linearly with this ratio. However, this linear dependence was not maintained for higher $S / V$ ratios. The $S / V$ ratios of 10 and $20 \mathrm{~cm}^{-1}$ were obtained by coiling the strip sample and immersing it in a glass vial with a relatively little amount of solution. Because of the coiling, it is possible 


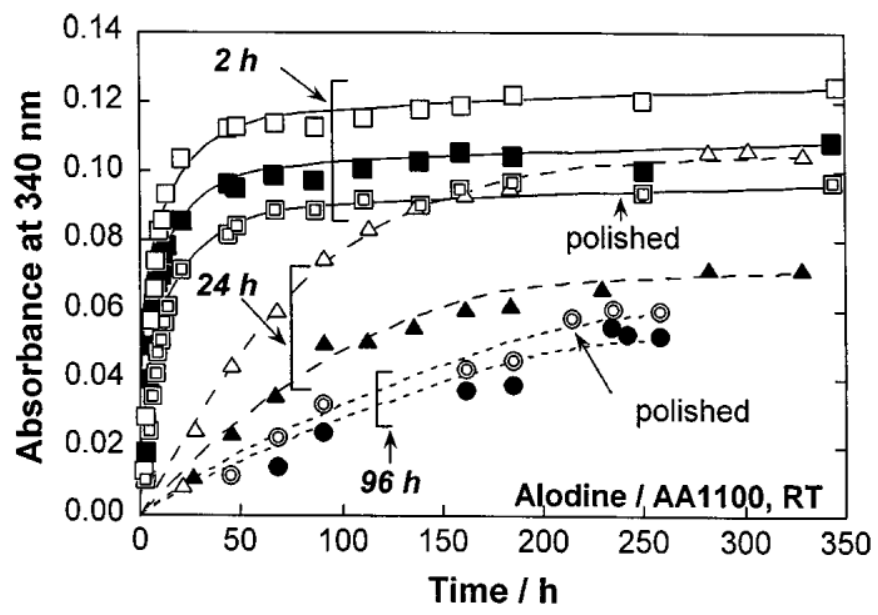

Figure 2. Comparison of chromate release curves of CCCs on AA1100 aged at room temperature for 2, 24, or $96 \mathrm{~h}$. CCC samples were immersed in DI water (solid symbols) or $0.1 \mathrm{M} \mathrm{NaCl}$ solution (open symbols). Chromate release curves of CCC samples polished slightly by $\mathrm{SiC}$ paper before immersion were also measured in DI water to note the effect of damaging the surface of the CCCs (double squares and double circles).

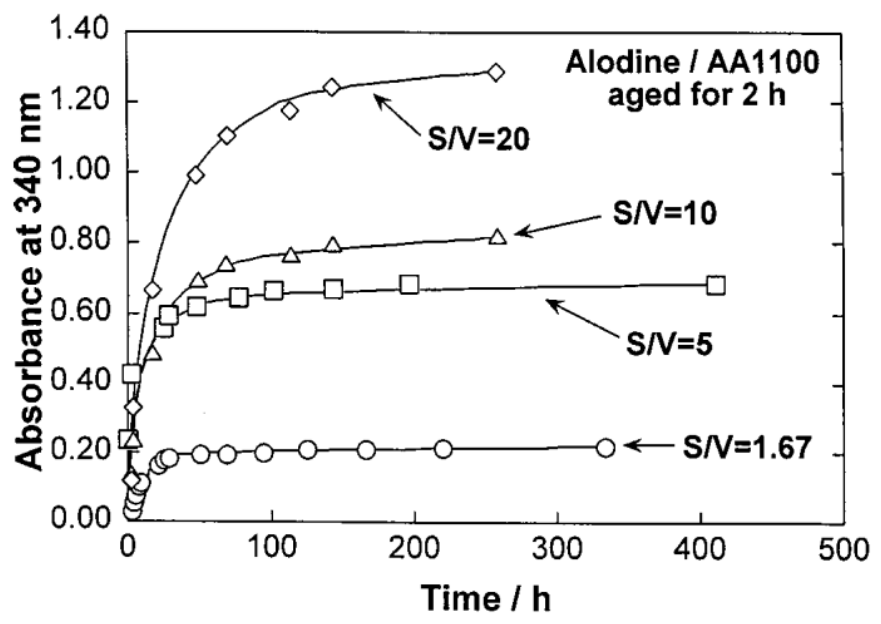

Figure 3. Chromate release from CCCs on AA1100 aged at room temperature for $2 \mathrm{~h}$. The $S / V$ ratio was changed from 1.67 to $20 \mathrm{~cm}^{-1}$.

that not all regions of the sample surface had access to the water or that the $\mathrm{Cr}(\mathrm{VI})$ concentration was inhomogeneous in the solution. Nonetheless, the measured concentration of $\mathrm{Cr}(\mathrm{VI})$ continued to increase with $S / V$ and did not exhibit a limiting value indicative of solution saturation. Accordingly, the plateau of the chromate release curves with time must be determined by something other than saturation of the solution with chromate. One possibility, as described the section on the release model, is that the chromate solution concentration limit is a result of a Langmuir-type adsorption equilibrium with chromate in the CCC.

Careful examination shows that the concentration of $\mathrm{Cr}(\mathrm{VI})$ in Fig. 3 for $S / V=1.67 \mathrm{~cm}^{-1}$ is roughly twice that in Fig. 2 for the same $S / V$. The samples in Fig. 2 were treated in an Alodine 
solution stored for a long period of time, about 1 year, whereas the samples in Fig. 3 were made in fresh Alodine solutions. The details of sample preparation obviously can greatly affect their behavior. We were unable to investigate this discrepancy further; the samples discussed hereafter were all made in fresh Alodine solutions.

Effect of substrate.-Figure 4 shows Cr(VI) release from CCCs formed on AA1100 and AA2024-T3 substrates. The release of chromates from CCCs on AA2024-T3 is slightly lower

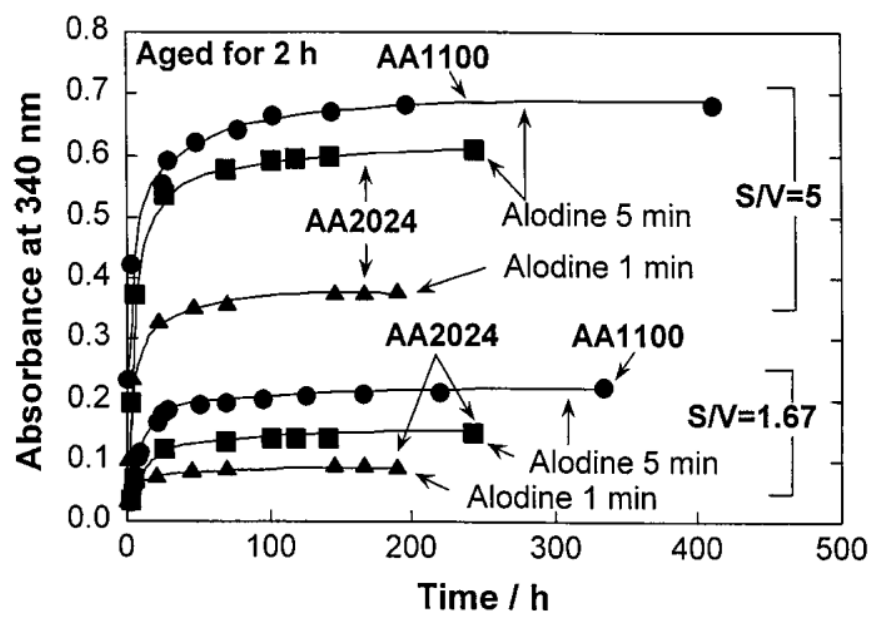

Figure 4. Chromate release curves of CCCs formed on AA1100 and AA2024 and aged at room temperature for $2 \mathrm{~h}$. The $S / V$ ratio was 1.67 or $5 \mathrm{~cm}^{-1}$. The curves of CCCs on AA2024 formed by an immersion in Alodine bath for 1 or 5 min are compared.

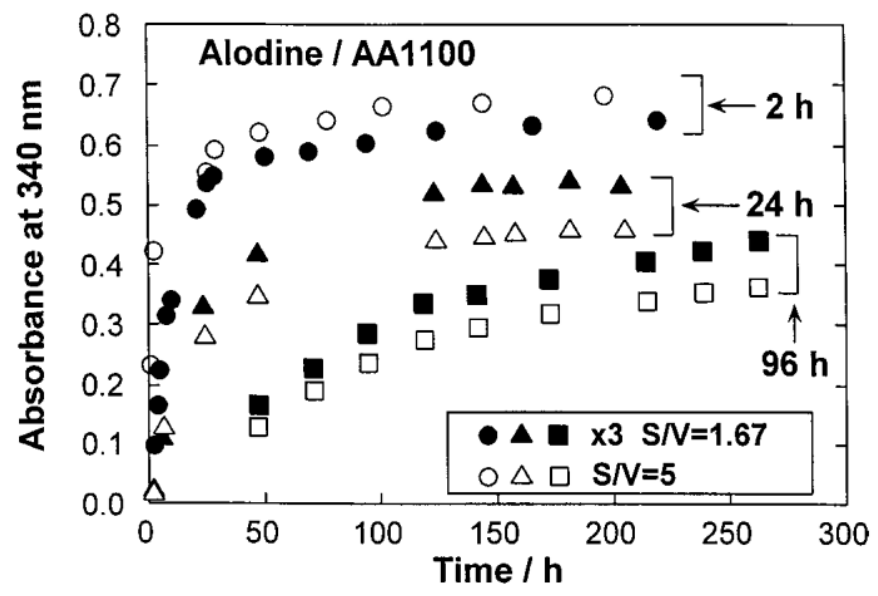

Figure 5. Comparison of release curves of CCCs on AA1100 aged for different periods of time. The absorbance for $S / V=3$ was multiplied by 3 .

than that from CCCs on AA1100, which indicates that the CCCs on different substrates are 
different in nature. McCreery and co-workers have shown that the accelerating influence of ferricyanide in Alodine solutions is reduced on $\mathrm{Cu}$ and $\mathrm{Cu}$-rich surfaces, such as would be found at the intermetallic particles, as a result of adsorption of $\mathrm{Fe}(\mathrm{CN})_{6}^{3-8,9}$ This complex apparently inhibited electron transfer at the surface, thus decreasing $\mathrm{Cr}(\mathrm{III})$ generation and $\mathrm{CCC}$ formation. The CCC on AA2024-T3 prepared by a 5 min immersion in Alodine bath showed a higher release of chromate than that from a sample given only a $1 \mathrm{~min}$ chromate treatment. This suggests that the amount of soluble $\mathrm{Cr}(\mathrm{VI})$ increased with increasing immersion time in the Alodine solution.

Release kinetics.-To see the effect of the $S / V$ ratio on release behavior, the UV absorption was normalized. Figure 5 shows a comparison of the chromate release for $S / V=5 \mathrm{~cm}^{-}$ ${ }^{1}$ and three times the chromate release for $S / V=1.67 \mathrm{~cm}^{-1}$. After this normalization, the release curves were almost identical. Therefore, the kinetics of chromate release and the total amount of chromate (not the concentration in solution) were approximately independent of $S / V$.

To further investigate the cause of the plateau in the release curves, a second sample made by the same procedure was added to a cell containing a sample that had been exposed for about $400 \mathrm{~h}$ of immersion at $S / V=5 \mathrm{~cm}^{-1}$ (see Fig. 6). The first sample was kept in the solution, so that the final $S / V$ ratio was $10 \mathrm{~cm}^{-1}$. The concentration of $\mathrm{Cr}(\mathrm{VI})$ started to increase again after the addition of the second sample. In another experiment, the solution of a sample with $S / V=$ $1.67 \mathrm{~cm}^{-1}$ was exchanged for fresh DI water after more than $300 \mathrm{~h}$ of immersion. A very small amount of $\mathrm{Cr}(\mathrm{VI})$ was found in the solution after the exchange. The further increase in chromate concentration with the addition of another sample supports our previous suggestion that the plateau concentration of $\mathrm{Cr}(\mathrm{VI})$ does not correspond to saturation. The fact that additional chromate was released when an equilibrated sample was placed in a fresh water solution indicates that the original steady state was not determined by depletion of chromate in the CCC. However, the amount released into the replaced DI water was less than that released into the original solution because the $\mathrm{Cr}(\mathrm{VI})$ concentration in the film was lower as a result of the first exposure.

The release curves were normalized in another fashion in Fig. 7. Here, the concentration was normalized by the concentration at the plateau, $C(\infty)$, to study the release kinetics. Curves of normalized concentration changed considerably with aging time, but they were not strongly influenced by the $S / V$ ratio. This suggests that the release of $\mathrm{Cr}(\mathrm{VI})$ was related to the structure of the film, which may have affected diffusion of chromates in the CCC. 


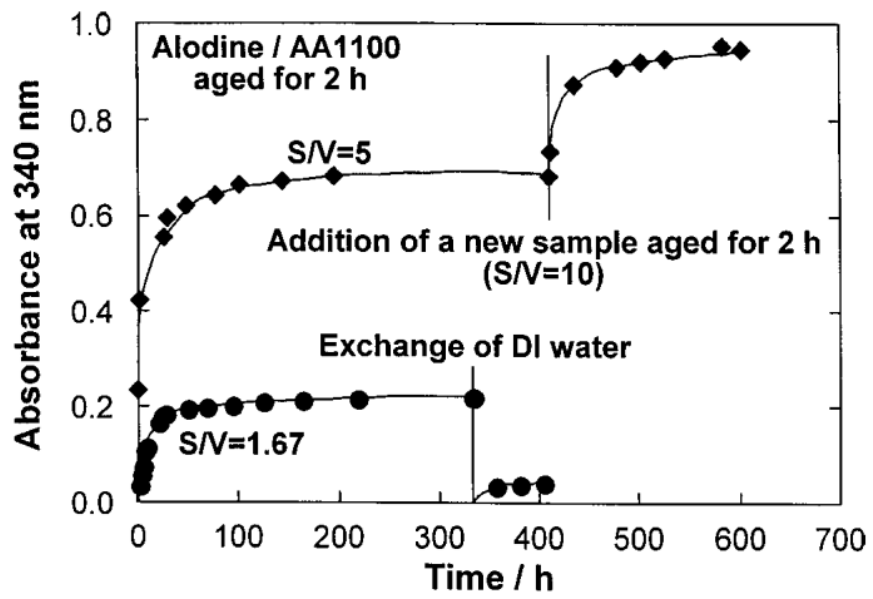

Figure 6. Effects of addition of a new CCC sample on AA1100 with $50 \mathrm{~cm}^{2}$ of surface area into $10 \mathrm{~cm}^{3}$ of solution where a CCC on AA1100 with $50 \mathrm{~cm}^{2}$ of surface area was immersed for about $400 \mathrm{~h}$. The total $S / V$ ratio after the addition of a new sample was 10. The other curve shows the change in the concentration of chromates by changing the solution to one of fresh DI water after an immersion of a CCC on AA1100 ( $/ V$ of $\left.1.67 \mathrm{~cm}^{-1}\right)$ for more than 300 h.

Release model.-In a previous paper, the steady-state solution concentrations were shown to be a result of a Langmuir-type equilibrium with $\mathrm{Cr}(\mathrm{VI})$ species adsorbed on the CCC. ${ }^{4}$ However, the fact that a sample treated for a longer time resulted in a higher solution concentration suggests that the CCC is not a two-dimensional surface with chromate adsorption sites, but that $\mathrm{Cr}$ (VI) binds to $\mathrm{Cr}$ (III) throughout a three-dimensional (3D) porous $\mathrm{Cr}$ (III) film. A diffusion model was developed assuming Langmuir-type equilibrium between dissolved $\mathrm{Cr}(\mathrm{VI})$ and a 3D CCC film. This model accounts for all of the observations previously described.

The basis for the model is shown in Fig. 8. The structure of a CCC in contact with an aqueous solution is considered to be a $3 \mathrm{D}$ porous $\mathrm{Cr}(\mathrm{III})$ matrix or backbone with chromate adsorption sites and an interpenetrating aqueous phase. The chromate concentrations in the aqueous phase within the $\mathrm{CCC}$ and the adsorbed $\mathrm{Cr}(\mathrm{VI}),[\mathrm{Cr}(\mathrm{VI})(\mathrm{aq})]$ and [Cr(VI)(ad)], respectively, can be functions of time and depth from the metal/CCC to the $\mathrm{CCC} /$ bulk-solution interfaces. The depth distribution of $\mathrm{Cr}(\mathrm{VI})$ is assumed to change with immersion time, as shown by the curves in the figure. $\mathrm{Cr}(\mathrm{VI})$ at the $\mathrm{CCC} /$ bulk-solution interface dissolves into the bulk 


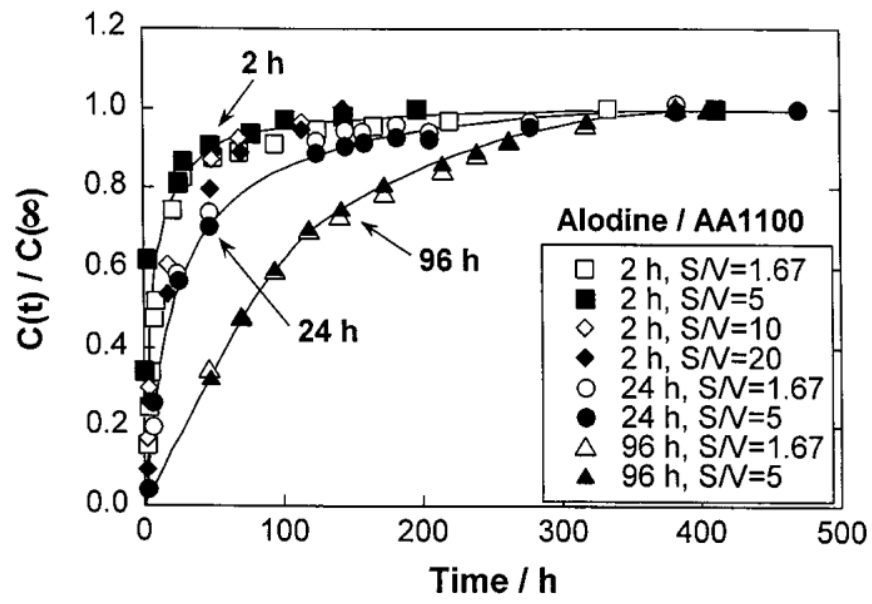

Figure 7. Change in normalized concentration of $\mathrm{Cr}(\mathrm{VI})$ as a function of immersion time. The concentration was normalized by the concentration at the plateau, $C(\infty)$.

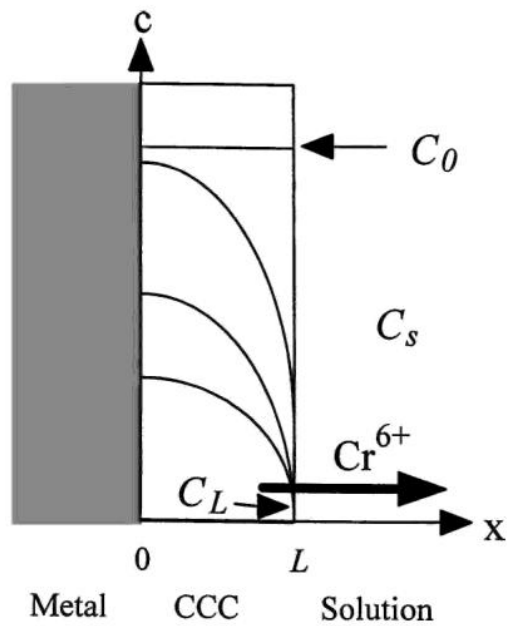

Figure 8. Schematic of the release model controlled by diffusion and Langmuir-type equilibrium of Cr(VI) species.

solution and is replenished by outward diffusion of $\mathrm{Cr}(\mathrm{VI})$ in the aqueous phase of the CCC. Diffusion in the bulk solution is ignored; the bulk solution is assumed to be homogeneous. Locally within the CCC structure, a Langmuir-type equilibrium is established between the $\mathrm{Cr}(\mathrm{VI})$ adsorbed on the $\mathrm{CCC}$ backbone and chromate in the aqueous phase within the CCC

$$
\mathrm{Cr}(\mathrm{VI})(\mathrm{ad}) \leftrightarrows \mathrm{Cr}(\mathrm{VI})(\mathrm{aq})
$$

It is assumed that this Langmuir-type adsorption/desorption equilibrium is fast compared 
to diffusion in the aqueous phase of the CCC. The binding energy of the adsorbed species is large corresponding to the formation of covalent bonds. This means that the rate constant for adsorption is much higher than that of desorption, so $[\mathrm{Cr}(\mathrm{VI})(\mathrm{aq})]<[\mathrm{Cr}(\mathrm{VI})(\mathrm{ad})]$, and the effective diffusivity should be relatively small.

$[\mathrm{Cr}(\mathrm{VI})(\mathrm{aq})]$ and $[\mathrm{Cr}(\mathrm{VI})(\mathrm{ad})]$ are related locally in the $\mathrm{CCC}$ according to the equilibrium of Reaction 1. Because of the interchange of $\mathrm{Cr}(\mathrm{VI})$ ions between the adsorption and desorption state, the diffusion equation for the system of chromate release from $\mathrm{CCC}$ is more complicated than the usual type of Fickian diffusion.

As discussed in detail in the Appendix, the diffusion of $\mathrm{Cr}(\mathrm{VI})$ species in $\mathrm{CCC}$ is described by

$$
\frac{\partial C_{\mathrm{f}}}{\partial \mathrm{t}}\left[1+\frac{\eta^{2} \rho}{\left(C_{\mathrm{f}}+\eta \rho\right)^{2}}\right]=D \frac{\partial^{2} C_{\mathrm{f}}}{\partial x^{2}}
$$

where $C_{\mathrm{f}}(=[\mathrm{Cr}(\mathrm{VI})(\mathrm{aq})])$ is the chromate concentration in the aqueous phase of the CCC film, $\eta$ is the number of the adsorption sites in a unit volume, and $\mathrm{p}$ is the ratio of desorption to adsorption rate constants, $k_{2} / k_{1}$. The concentration of adsorbed chromate, $C_{\mathrm{a}}(=[\mathrm{Cr}(\mathrm{VI})(\mathrm{ad})])$, and the total chromate concentration, $C(=[\mathrm{Cr}(\mathrm{VI})(\mathrm{aq})]+[\mathrm{Cr}(\mathrm{VI})(\mathrm{ad})])$, at a particular $x$ and $t$ are known by

$$
C_{\mathrm{a}}=C-C_{\mathrm{f}}=\eta \theta=\frac{\eta k_{1} C_{\mathrm{f}}}{k_{1} C_{\mathrm{f}}+k_{2} \eta}=\frac{\eta C_{\mathrm{f}}}{C_{\mathrm{f}}+\eta \rho}
$$

The boundary conditions are as follows

$$
\frac{\partial C_{\mathrm{f}}}{\partial x}(0, t)=0, C_{\mathrm{f}}(L, t)=C_{\mathrm{s}}(t)=-D \frac{S}{V} \int_{0}^{\mathrm{t}} \frac{\partial C_{\mathrm{f}}}{\partial x}(L, t) d t
$$

where $C_{\mathrm{s}}$ is the concentration of $\mathrm{Cr}(\mathrm{VI})$ in the bulk solution, $S$ is the surface area of the CCC, $V$ is the volume of the bulk solution, and $L$ is the film thickness of the CCC. Due to the timedependent boundary condition on the right side of Eq. 4, it is difficult to obtain a solution expressed by an equation and to estimate unknown parameters by curve fitting. A program was written to solve these equations and to plot the predicted solution concentration of $\mathrm{Cr}(\mathrm{VI})$ as a function of time. 


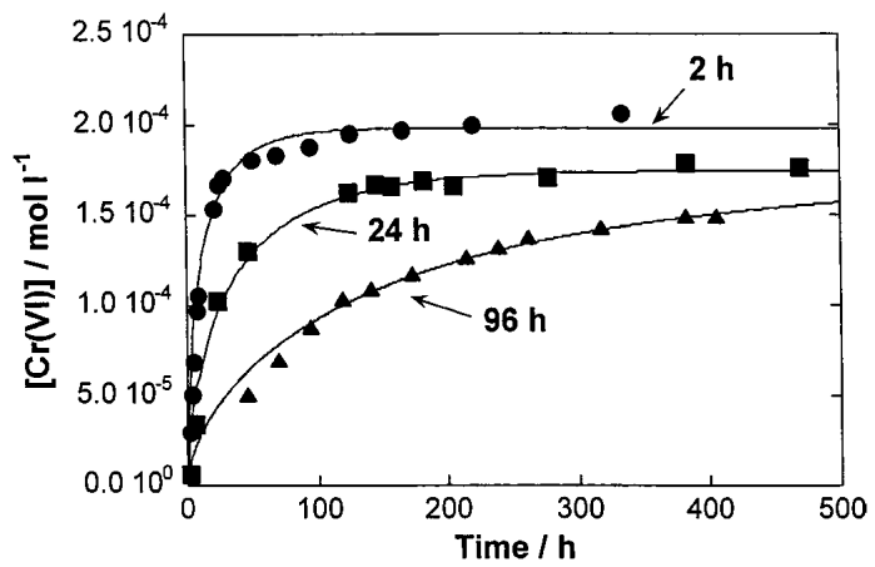

Figure 9. Comparison between fitted curves of the model and the experimental data for CCCs on AA1100 aged for 2,24 , or $96 \mathrm{~h}$. The curves were calculated by using the proposed model assuming that $\mathrm{p}, r$, and the CCC thickness are $1.0 \times 10^{-3}, 1.5 \times 10^{-3} \mathrm{~mol} \mathrm{~cm}^{-3}$, and $1.2 \times 10^{-4} \mathrm{~cm}$, respectively. $C_{0}$ is $1.2 \times 10^{-3}, 1.06 \times 10^{-3}$, and $1.06 \times 10^{-3} \mathrm{~mol}$ $\mathrm{cm}^{-3}$ for 2,24 , and $96 \mathrm{~h}$ of aging time, respectively, and $D$ is $4 \times 10^{-11}, 1.6 \times 10^{-11}$, and $0.35 \times 10^{-11} \mathrm{~cm}^{2} \mathrm{~s}^{-1}$, for 2, 24, and $96 \mathrm{~h}$ of aging time, respectively.

It was previously reported that the chromate release was consistent with a mechanism similar to a Langmuir adsorption isotherm

$$
\frac{\Gamma_{\mathrm{VI}}}{\Gamma_{\mathrm{s}}-\Gamma_{\mathrm{VI}}}=\beta\left[\mathrm{Cr}^{6+}\right]\left[\mathrm{H}^{+}\right]=\frac{\theta}{1-\theta}
$$

where $\Gamma_{\mathrm{VI}}$ is the coverage of $\mathrm{Cr}(\mathrm{VI})$ on the $\mathrm{Cr}(\mathrm{III})$ oxide in $\mathrm{mol} \mathrm{cm}^{-2}, \beta$ is a binding constant, and $\theta$ is the fractional coverage of $\mathrm{Cr}(\mathrm{VI})$. However, when the rates of adsorption and desorption are the same

$$
k_{1}\left[\mathrm{Cr}^{6+}\right](1-\theta)=k_{2} \eta \theta
$$

Note that $k_{1}$ is proportional to $\left[\mathrm{H}^{+}\right]$. Owing to its high mobility, it is assumed that $\left[\mathrm{H}^{+}\right]$is independent of the depth and time. From Eq. 5 and 6

$$
\beta\left[\mathrm{H}^{+}\right]=\frac{k_{1}}{k_{2}} \frac{1}{\eta}=\frac{1}{\rho \eta}
$$

It has been reported that $\beta\left[\mathrm{H}^{+}\right]=10^{3} \mathrm{~mol}^{-1} \mathrm{~L}^{4}$ Therefore, it is predicted that $\rho \eta$ is roughly $10^{-6}$ mol cm$~^{-3}$. Fitting of the model to the experimental data was performed assuming that $\rho \eta$ is about $10^{-6} \mathrm{~mol} \mathrm{~cm}^{-3}$, and the diffusion coefficient, $D$, the initial concentration of $\left[\mathrm{Cr}^{6+}\right]$, and the film thickness were estimated. The values of $\rho$ (unitless) and $\eta\left(\mathrm{mol} \mathrm{cm}^{-3}\right)$ were varied from $1 \times 10^{-3}$ 
to $2 \times 10^{-3}$. The unknown parameters are the diffusion coefficient, $D$, the CCC film thickness, $L$, the number of the adsorption sites, $\eta$, and the ratio of rate constants, $k_{2} / k_{1}(=\rho)$. Sets of values of these parameters were input to the program for obtaining a numerical solution of the differential equation, Eq. 4, and the predicted $\mathrm{Cr}(\mathrm{VI})$ concentrations in the bulk solution as a function of time were fitted to the experimental data, providing estimated values of the parameters. $L, \rho$, and $\eta$ affect the plateau $\mathrm{Cr}(\mathrm{VI})$ concentration, but $D$ does not.

Figure 9 shows experimental data and curves calculated using a representative set of estimated values of parameters. The model predictions exhibit good agreement with the

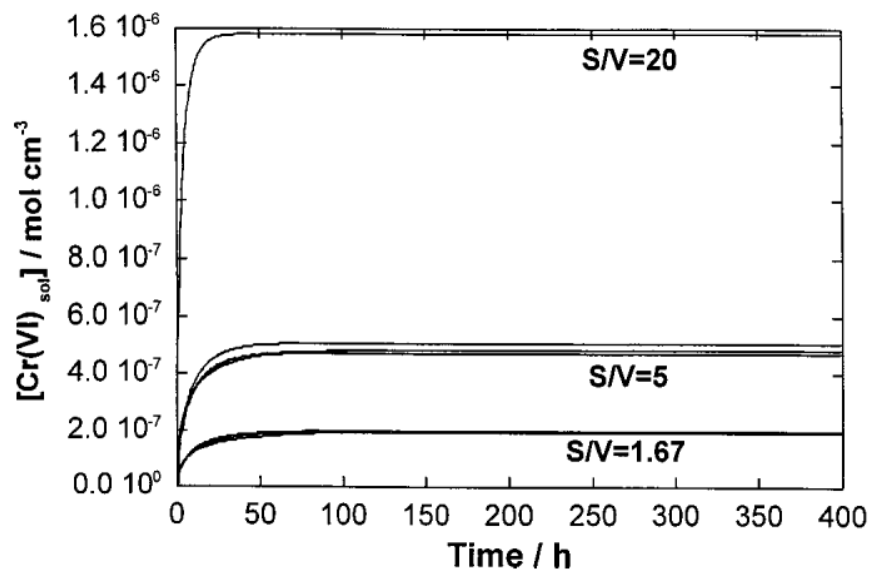

Figure 10. Curves calculated by using estimated values of parameters for $S / V=1.67,5$, and $20 \mathrm{~cm}^{-1}$.

experimental data, which indicates that the proposed diffusion model and values of parameters estimated are appropriate. This supports the assumptions that the $\mathrm{CCC}$ is a $3 \mathrm{D}$ porous $\mathrm{Cr}(\mathrm{III})$ matrix or backbone with chromate adsorption sites and an interpenetrating aqueous phase, and that the release kinetics are determined by the diffusion of chromate in the aqueous phase in conjunction with local Langmuir-type equilibrium. The effect of aging is addressed later in this section.

Chromate release curves calculated by using four different sets of estimated parameter values for $S / V=1.67$ and $5 \mathrm{~cm}^{-1}$ are shown in Fig. 10. Changing the parameter values had the largest effect for $S / V=20 \mathrm{~cm}^{-1}$, and the values used for the $20 \mathrm{~cm}^{-1}$ curve in Fig. 10 are those used to fit the data of $2 \mathrm{~h}$ aging time in Fig. 9: $\mathrm{p}=1.0 \times 10^{-3}, \eta=1.5 \times 10^{-3} \mathrm{~mol} \mathrm{~cm}^{-3}, \mathrm{CCC}$ thickness $=1.2 \times 10^{-4} \mathrm{~cm}$, and $D=4 \times 10^{-11} \mathrm{~cm}^{2} \mathrm{~s}^{-1}$. The model predicts that the plateau value of $\mathrm{Cr}(\mathrm{VI})$ concentration does not scale exactly linearly with $S / V$, which was found experimentally, as shown in Fig. 3. The model predicts an increase in release with $S / V$ ratio similar to the experimental data, suggesting that the estimated values of parameters are appropriate and that the $\mathrm{Cr}(\mathrm{VI})$ concentration limit results from a Langmuir-type adsorption equilibrium with $\mathrm{Cr}(\mathrm{VI})$ in the CCC.

It is possible to use the curves for different $S / V$ ratios to determine which sets of values apply best for each aging time. The estimated diffusion coefficients of CCC samples aged for various periods of time at room temperature are shown in Fig. 11. The bars in this figure (as well 


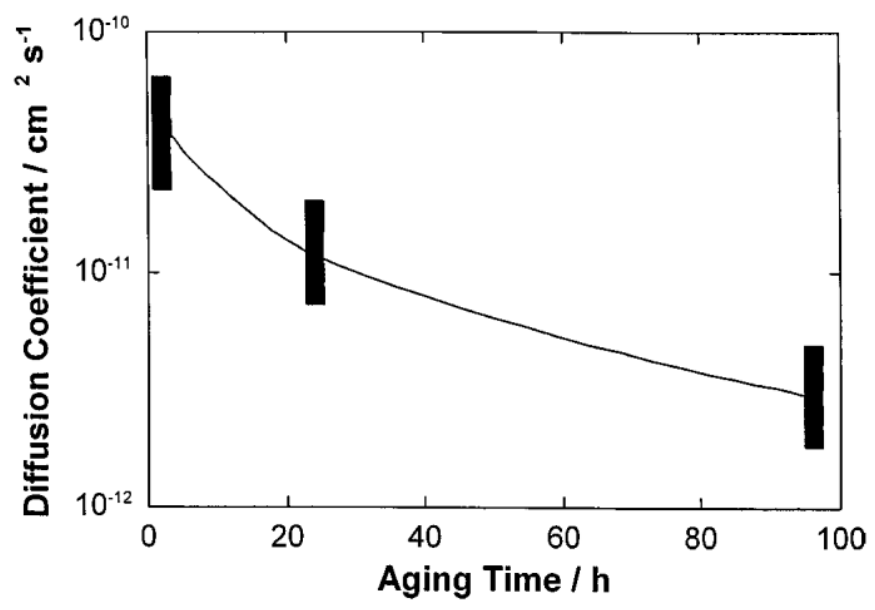

Figure 11. Estimated diffusion coefficient of $\mathrm{Cr}(\mathrm{VI})$ species in the CCCs on AA1100 as a function of aging time at room temperature.

as in some subsequent figures) represent the spread between the highest and lowest values found by fitting the numerical solution to experimental data; different sets of estimated values of parameters result in curves well fitted to the experimental data. The diffusion coefficient tends to decrease with increasing room-temperature aging time, suggesting that the CCC is modified with aging time.

From Eq. 2, the effective diffusivity of $\mathrm{Cr}(\mathrm{VI})$ in a $\mathrm{CCC}$ is given by

$$
D_{\text {eff }}=\frac{D}{1+\frac{\eta^{2} \rho}{\left(C_{\mathrm{f}}+\eta \rho\right)^{2}}}
$$

$D_{\text {eff }}$ is different than $D$ because of the interaction of $\operatorname{Cr}(\mathrm{VI})$ with the $\operatorname{Cr}(\mathrm{III})$ matrix; $D$ is the diffusion coefficient of $\mathrm{Cr}(\mathrm{VI})$ species in the aqueous phase of CCCs with no consideration of the influence of adsorption of $\mathrm{Cr}(\mathrm{VI})$ with the $\mathrm{Cr}(\mathrm{III})$ matrix. Figure 11 shows that the values for $D$ are on the order of $10^{-11} \mathrm{~cm}^{2} \mathrm{~s}^{-1}$, which is significantly lower than that expected for the diffusivity of $\mathrm{Cr}(\mathrm{VI})$ ions in bulk solutions. Therefore, the effective diffusivity within a CCC is reduced relative to that in a bulk solution by two factors: the effect of adsorption on the $\mathrm{Cr}$ (III) matrix, which is accounted for by the model, and the physical barrier nature of the CCC.

The difference between $D$ and typical diffusivities of ions in bulk solutions can be explained by the effect of the network structure of the $\mathrm{Cr}$ (III) matrix acting as a diffusion barrier. The CCC can be viewed as a biphase structure consisting of interpenetrating solid $\mathrm{Cr}$ (III) matrix and aqueous channels, and the pathways for $\mathrm{Cr}(\mathrm{VI})$ diffusion are the aqueous channels. These channels are apparently so tight and convoluted that they impede the transport of the soluble $\mathrm{Cr}(\mathrm{VI})$ species through the CCC. This effect is probably larger when the local $\mathrm{pH}$ is low and the dominant $\mathrm{Cr}(\mathrm{VI})$ species is the larger dichromate anion. Formation of hydrogen bonds may also affect the diffusion of $\mathrm{Cr}(\mathrm{VI})$ species. Room-temperature aging probably decreases the $\mathrm{Cr}(\mathrm{VI})$ 
diffusion coefficient in the CCC because of the formation of a multinuclear $\mathrm{Cr}$ (III)-O-Cr(III) structure that further impedes the diffusion of $\mathrm{Cr}(\mathrm{VI})$ species. The structure of CCCs and the effects of aging have recently been studied using extended X-ray absorption fine structure analysis. ${ }^{11}$ Aging resulted in a decrease in the $\mathrm{Cr}(\mathrm{III})-\mathrm{Cr}(\mathrm{III})$ nearest-neighbor distances, which is consistent with polymerization associated with dehydration. Note that it is possible to ignore aging effects during the immersion period, because structural rearrangement associated with dehydration would not occur.

It may be more appropriate to compare the diffusivity values to those for ions in polymers, which vary over a wide range, from approximately $10^{-7} \mathrm{~cm}^{2} / \mathrm{s}^{-1}$ in polymer electrolytes to near zero for immobile ions or neutrals. ${ }^{12-14}$ For example, polyethylene oxide electrolytes chosen for high ion mobility exhibit diffusion coefficients for small molecules of $3 \times 10^{-7}$ to $2 \times$ $10^{-8} \mathrm{~cm}^{2} / \mathrm{s}^{-1}$. Much smaller diffusion coefficients are expected for cross-linked polymers such as $\mathrm{Cr}(\mathrm{III})(\mathrm{OH})_{x}$, and the values are likely to decrease as the extent of cross-linking increases with time or heat-treatment. Therefore, the $D$ values shown in Fig. 11 are within an acceptable range for cross-linked polymers.

Figure 12 shows the effective diffusivity of $\mathrm{Cr}(\mathrm{VI})$ in the $\mathrm{CCC}$ on AA1100 as a function of room-temperature aging time, position within the $\mathrm{CCC}$, and time of immersion in water. The effective diffusivity decreases with immersion time owing to a decrease in both [Cr(VI)(aq)] and $[\mathrm{Cr}(\mathrm{VI})(\mathrm{ad})]$ as the $\mathrm{Cr}(\mathrm{VI})$ is released from the $\mathrm{CCC}$ into the bulk solution. The effective diffusivity is lower at the $\mathrm{CCC} /$ solution interface than at the $\mathrm{Al} / \mathrm{CCC}$ interface because of the $\mathrm{Cr}(\mathrm{VI})$ concentration gradient within the CCC, as is shown later in this section. The effect of room-temperature aging time is reflected in the change in $D$ shown in Fig. 11.

The estimated initial concentration of soluble $\mathrm{Cr}(\mathrm{VI})$ is shown in Fig. 13. The amount of soluble chromate in the $\mathrm{CCC}$ does not change markedly with aging time at room temperature, up

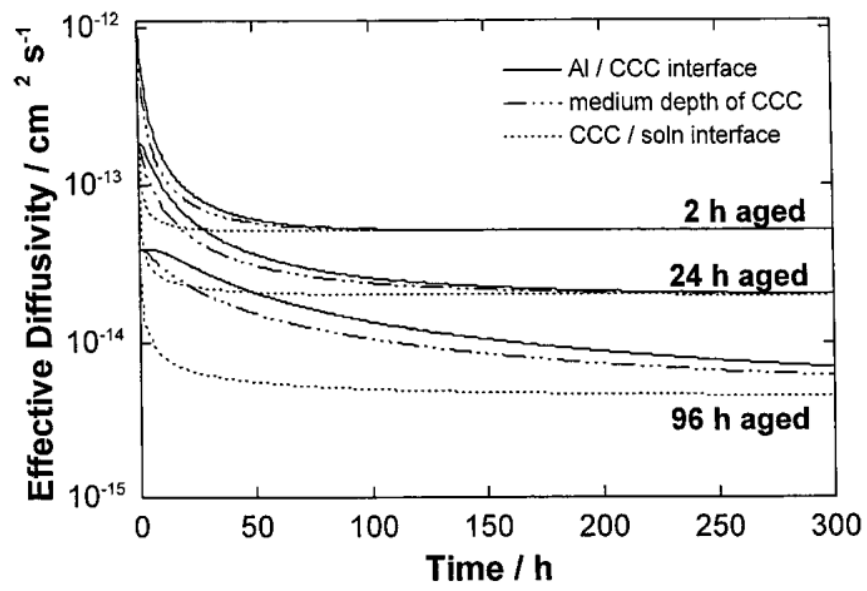

Figure 12. Effective diffusion coefficient of $\mathrm{Cr}(\mathrm{VI})$ species in the CCCs on AA1100 as a function of aging time at room temperature, location within the $\mathrm{CCC}$, and time of immersion in water.

to 4 days. This suggests that the $\mathrm{Cr}(\mathrm{VI})$ is not reduced to $\mathrm{Cr}(\mathrm{III})$ during room-temperature aging, does not form an insoluble product, and does not form an irreversible bond with the $\mathrm{Cr}(\mathrm{III})$ matrix species. Note that the situation changes after very long aging times. A CCC-treated panel 
of AA3003-H14 contained virtually no Cr(VI) by X-ray absorption near-end structure analysis. ${ }^{15}$ The estimated thickness of the CCC is shown in Fig. 14 as a function of aging time. The estimated CCC thickness was almost constant at approximately $1 \mu \mathrm{m}$, which corresponds with the reported CCC thickness.

Figure 15 shows the change in the concentration of adsorbed $\mathrm{Cr}(\mathrm{VI})$ on adsorption sites of $\mathrm{CCC}$ and free $\mathrm{Cr}(\mathrm{VI})$ in aqueous phase in $\mathrm{CCC}$ as a function of immersion time. Because the binding of $\mathrm{Cr}(\mathrm{VI})$ to $\mathrm{Cr}(\mathrm{III})$ is strong, ${ }^{4} \mathrm{Cr}(\mathrm{VI})$ species exist primarily as adsorbed $\mathrm{Cr}(\mathrm{VI})$ in the CCC. The shape of the adsorbed Cr(VI) curves is similar to those of free Cr(VI) because local equilibrium is assumed. The relationship between adsorbed $\mathrm{Cr}(\mathrm{VI})$ and free $\mathrm{Cr}(\mathrm{VI})$ is expressed by Eq. A-7 in the Appendix. The depth profiles of free Cr(VI) in CCC aged for 2 or $96 \mathrm{~h}$ derived from the model calculation are shown in Fig. 16 (top) and (bottom), respectively. Because the main difference between 2 and $96 \mathrm{~h}$ aged CCCs is in the value of the diffusion coefficient, the shapes of the depth profiles are basically similar to each other, although the time scale is different. The $\mathrm{Cr}(\mathrm{VI})$ concentration at the surface of the CCC at the initial stages of immersion is

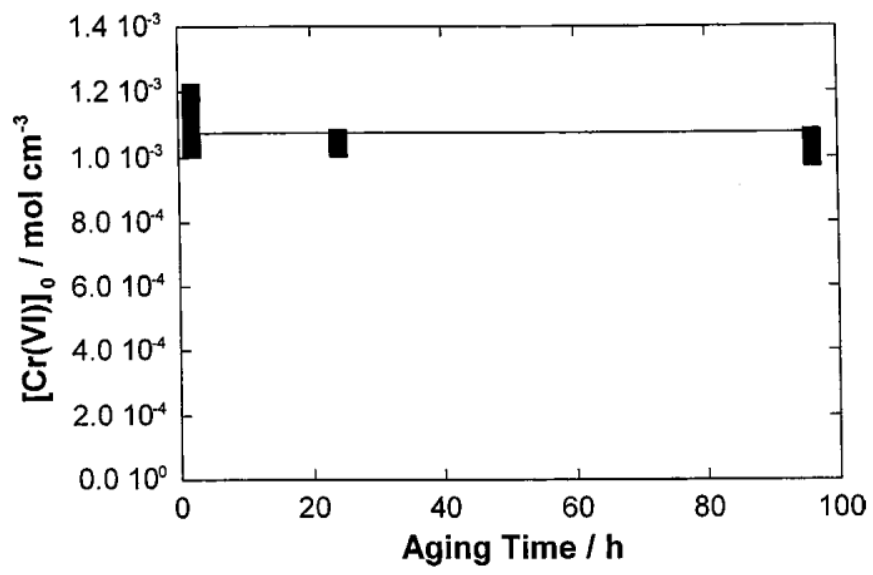

Figure 13. Estimated initial concentration of $\mathrm{Cr}(\mathrm{VI})$ contained in $\mathrm{CCCs}$ on $\mathrm{AA} 1100$ as a function of aging time at room temperature.

smaller than that at longer times because the $\mathrm{Cr}(\mathrm{VI})$ concentration in bulk solution is initially 0 and gradually increases by the $\mathrm{Cr}(\mathrm{VI})$ release from CCC. At higher $S / V$ ratios, the change of $\mathrm{Cr}$ (VI) concentration at the CCC surface is larger. 


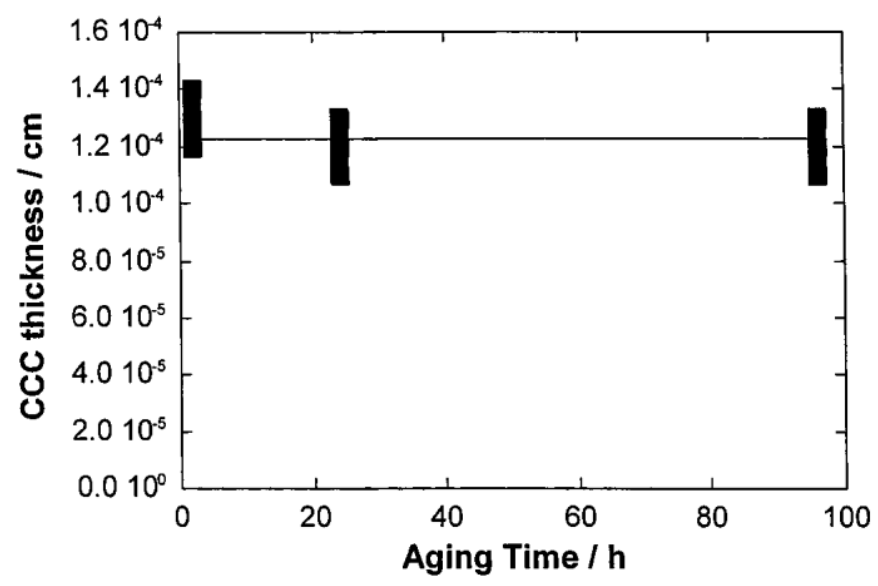

Figure 14. Estimated thickness of CCCs on AA1100 aged for 2, 24, or $96 \mathrm{~h}$.

Implications of model. - This release model supports the view of a $\mathrm{CCC}$ as a 3D porous $\mathrm{Cr}$ (III) matrix or backbone with chromate adsorption sites and an interpenetrating aqueous phase. Release of $\mathrm{Cr}(\mathrm{VI})$ from this biphase structure is driven by a Langmuir-type equilibrium of the $\mathrm{CCC}$ at the film/bulk-solution interface, and the release kinetics are determined by the diffusion of chromate in the aqueous phase in conjunction with a local Langmuir-type equilibrium.

From the corrosion point of view, this model provides important implications as to how $\mathrm{Cr}(\mathrm{VI})$ releases in the field. $\mathrm{SrCrO}_{4}$ pigment in paint does not form a Langmuir-type interaction with the solution in which it is contact; chromate pigment releases $\mathrm{Cr}(\mathrm{VI})$ until the solution is saturated. When $\mathrm{Cr}(\mathrm{VI})$ in the surface solution reduces to $\mathrm{Cr}(\mathrm{III})$ for corrosion protection of a nearby metal, the remaining $\mathrm{SrCrO}_{4}$ solid releases more $\mathrm{Cr}(\mathrm{VI})$ to maintain saturation. The 


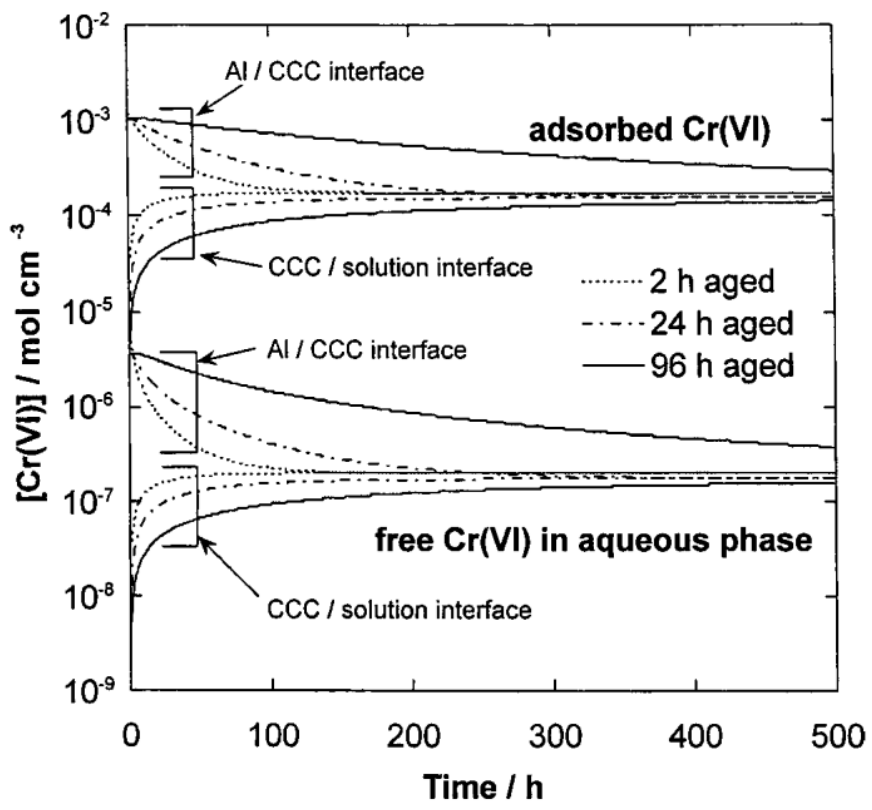

Figure 15. Change in the concentration of adsorbed $\mathrm{Cr}(\mathrm{VI})$ and free $\mathrm{Cr}(\mathrm{VI})$ in aqueous phase at the Al1 100/CCC interface and at the CCC/solution interface for CCCs aged 2, 24, or $96 \mathrm{~h}$. The curves were obtained by using the values of parameters used in Fig. 9. 


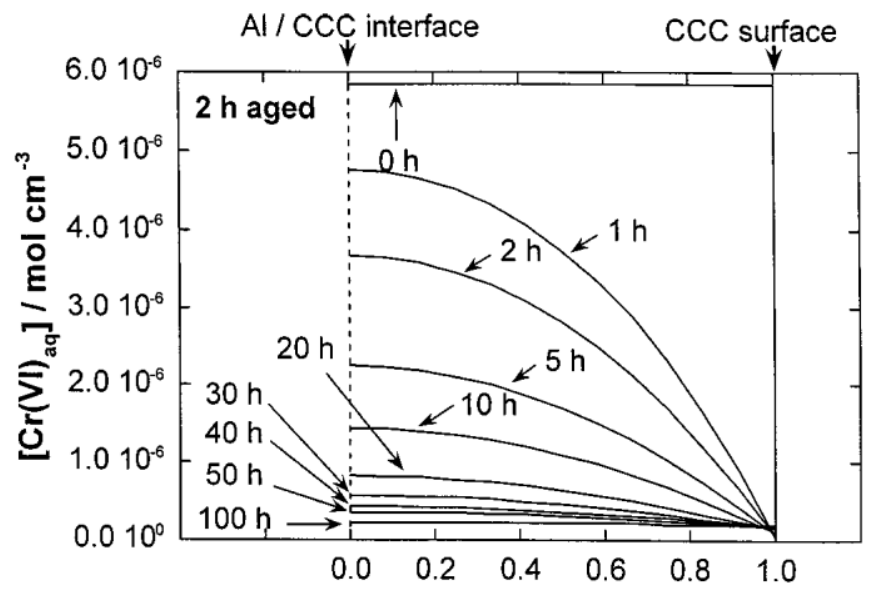

Normalized Distance from Al / CCC Interface

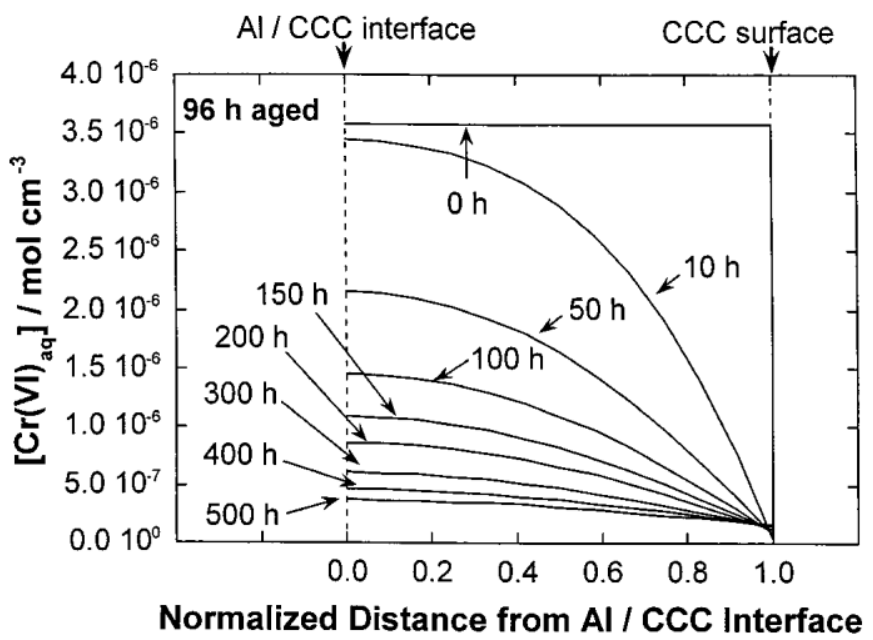

Figure 16. The in-depth profile of free $\mathrm{Cr}(\mathrm{VI})$ in aqueous phase in CCC aged at room temperature (Top) Aged for 2 h. $\mathrm{Cr}(\mathrm{VI})$ profile at various immersion times is plotted. The curves were obtained by using the values of parameters used in Fig. 9 and 14. (Bottom) Aged for $96 \mathrm{~h}$.

solution remains saturated until the $\mathrm{SrCrO}_{4}$ is fully consumed. For CCCs, the equilibrium $\mathrm{Cr}(\mathrm{VI})$ solution concentration depends on the $S / V$ ratio, surface $\mathrm{Cr}(\mathrm{VI})$ concentration, and solution $\mathrm{pH}$, etc. Release of $\mathrm{Cr}(\mathrm{VI})$ from the CCC film results in a lower surface $\mathrm{Cr}(\mathrm{VI})$ concentration. As $\mathrm{Cr}(\mathrm{VI})$ in the solution is consumed, the equilibrium $\mathrm{Cr}(\mathrm{VI})$ solution concentration decreases. The total amount of chromate in pigmented paint is usually far in excess of the amount in a CCC. However, for a $\mathrm{CCC}$ and $\mathrm{SrCrO}_{4}$ pigment containing the same amount of $\mathrm{Cr}(\mathrm{VI})$, the $\mathrm{CCC}$ film lasts longer because of the different type of equilibrium reached with the solution.

As shown in Fig. 2, $\mathrm{NaCl}$ addition to DI water enhanced $\mathrm{Cr}(\mathrm{VI})$ release. It seems that chloride anions inhibit the reversible binding of $\mathrm{Cr}(\mathrm{VI})$ to hydrated chromium hydroxide,${ }^{16}$ so that the diffusivity of chromates is enhanced. The higher release rate in the presence of corrosive chloride ions is useful from the viewpoint of corrosion protection. 


\section{Conclusions}

Release of chromate from CCC was verified by UV absorption measurements. Heattreatment of CCC markedly reduced the ion release rate. The release rate of chromates from $\mathrm{CCC}$ decreased with aging time at room temperature.

A diffusion model was proposed in conjunction with a local Langmuir-type equilibrium with an interpenetrating solution phase. Using this model, the diffusion coefficient of chromates in the CCC, the CCC thickness, and the initial concentration of $\mathrm{Cr}(\mathrm{VI})$ were estimated. The diffusion coefficient decreased with aging time at room temperature, presumably because of the development of the CCC matrix.

\section{Acknowledgments}

This work was supported under Air Force Office of Scientific Research Multidisciplinary University Research Initiative contract no. F49620-96-1-0479.

The Ohio State University assisted in meeting the publication costs of this article.

\section{Appendix}

\section{Diffusion of Hexavalent Chromium in CCC}

The total concentration of $\mathrm{Cr}^{\mathrm{VI}}$ within the coating is a function of the position, $x$, and the immersion time, $t$, and is given by $C(x, t)$, with $x=0$ at the metal/coating interface and $x=L$ at the coating/solution interface. In general, $C$ is comprised of two contributions, i.e., the concentration $C_{\mathrm{f}}$ of $\mathrm{Cr}^{\mathrm{VI}}$ that is free to diffuse, and the concentration $C_{\mathrm{a}}$ that is adsorbed on any of the $\eta$ adsorption sites available per unit volume of the film. We assume that $\eta$ is independent of $x$ and $t$. Hence

$$
C(x, t)=C_{\mathrm{f}}(x, t)+C_{\mathrm{a}}(x, t)
$$

Adsorption kinetics - We assume that $C_{\mathrm{f}}$ and $C_{\mathrm{a}}$ are related by simple Langmuir-type adsorption kinetics. In that regard, consider a thin "slab" of coating extending from $x$ to $x+d x$. The number of adsorption sites per unit area of this slab is $\eta d x$. Let $\Theta(x, t)$ be the fraction of these sites occupied by adsorbed $\mathrm{Cr}^{\mathrm{IV}}$, from which we deduce that

$$
C_{\mathrm{a}} d x=\eta d x \theta \text { or } C_{\mathrm{a}}=\eta \theta
$$

We consider the insoluble $\mathrm{Cr}$ (III) to have many surface hydroxyl groups available for formation of $\mathrm{Cr}$ (III) - $\mathrm{O}-$ $\mathrm{Cr}(\mathrm{VI})$ bonds. These hydroxyl groups act as sites for adsorption of $\mathrm{Cr}(\mathrm{VI})$, accompanied by the addition of a hydrogen ion to produce water. The reaction may be represented by ${ }^{4}$

$$
\begin{aligned}
& \mathrm{Cr}(\mathrm{III})-\mathrm{OH}+\mathrm{Cr}(\mathrm{VI})(\mathrm{aq}) \\
& \quad+\mathrm{H}^{+}(\mathrm{aq}) \underset{k_{2}}{\stackrel{k_{1}}{\rightleftarrows}} \mathrm{Cr}(\mathrm{III})-\mathrm{O}-\mathrm{Cr}(\mathrm{VI})(\mathrm{ad})+\mathrm{H}_{2} \mathrm{O} \quad \text { [A-3-1] }
\end{aligned}
$$

$\mathrm{Cr}(\mathrm{III})-\mathrm{OH}$ represents insoluble $\mathrm{Cr}(\mathrm{III})$ oxyhydroxide, $\mathrm{Cr}(\mathrm{VI})(\mathrm{aq})$ is solution-phase $\mathrm{Cr}(\mathrm{VI})$ species which include oxygen atoms, and $\mathrm{Cr}(\mathrm{III})-\mathrm{O}-\mathrm{Cr}(\mathrm{VI})$ is the adsorbed state of $\mathrm{Cr}(\mathrm{VI})$ to $\mathrm{Cr}(\mathrm{III})$ by oxygen. Note that $\mathrm{Cr}(\mathrm{VI})(\mathrm{aq})$ has one oxygen atom more than $\mathrm{Cr}(\mathrm{VI})(\mathrm{ad})$.

The reaction is reversible, so the $\mathrm{CCC}$ may release $\mathrm{Cr}(\mathrm{VI})$, and the $\mathrm{Cr}(\mathrm{III})$ oxyhydroxide may adsorb 
$\mathrm{Cr}(\mathrm{VI})$ from the aqueous phase. Considering the existence of $\mathrm{Cr}_{2} \mathrm{O}_{7}^{2-}$ as a $\mathrm{Cr}(\mathrm{VI})$ species, the reaction of insoluble $\mathrm{Cr}(\mathrm{III})$ oxyhydroxide with $\mathrm{Cr}_{2} \mathrm{O}_{7}^{2-}$ can be expressed by Reaction A-3-2. ${ }^{16}$ Two $\mathrm{Cr}$ (III) are connected with each other by two ol-bridges

$$
\begin{aligned}
& 2 \mathrm{Cr}(\mathrm{III})-\mathrm{OH}+\mathrm{Cr}_{2}(\mathrm{VI}) \mathrm{O}_{7}^{2-} \\
& +2 \mathrm{H}^{+}(\mathrm{aq}) \underset{k_{2}^{\prime}}{\stackrel{k_{1}^{\prime}}{\rightleftarrows}} 2[\mathrm{Cr}(\mathrm{III})-\mathrm{O}]-\mathrm{Cr}_{2}(\mathrm{VI}) \mathrm{O}_{7}+2 \mathrm{H}_{2} \mathrm{O} \quad[\mathrm{A}-3-2]
\end{aligned}
$$

From the stoichiometric point of view, Reactions A-3-1 and A-3-2 are basically the same.

The adsorption/desorption reactions within the slab are described as follows

$$
\begin{aligned}
& \text { Rate of adsorption }=k_{1} C_{\mathrm{f}}(1-\theta) \\
& \text { Rate of desorption }=k_{2} C_{\mathrm{a}}=k_{2} \eta \theta
\end{aligned}
$$

where $k_{1}$ and $k_{2}$ are rate constants, with $k_{1}$ being proportional to $\left[\mathrm{H}^{+}\right]$. It is assumed that $C_{\mathrm{a}}>C_{\mathrm{f}}$ because the binding energy of the adsorption is high, corresponding to chemisorption. ${ }^{4}$ We assume that $\left[\mathrm{H}^{+}\right]$is independent of $x$ and $t$. Langmuir-type kinetics involves taking the two rates to be equal

$$
\theta=\frac{k_{1} C_{\mathrm{f}}}{k_{1} C_{\mathrm{f}}+k_{2} \eta} \text { or } \frac{k_{1} C_{\mathrm{f}}}{k_{2} \eta}=\frac{\theta}{1-\theta} \quad[\mathrm{A}-6]
$$

We can now establish a relationship between $C_{\mathrm{f}}$ and $C$, i.e.

$$
C_{\mathrm{a}}=C-C_{\mathrm{f}}=\eta \theta=\frac{\eta k_{1} C_{\mathrm{f}}}{k_{1} C_{\mathrm{f}}+k_{2} \eta}=\frac{\eta C_{\mathrm{f}}}{C_{\mathrm{f}}+\eta \rho} \quad[\mathrm{A}-7]
$$

where $\rho=k_{2} / k_{1}$. Note that $C_{\mathrm{a}}<\eta$, as expected. We now have the following quadratic equation

$$
\begin{gathered}
\left(C-C_{\mathrm{f}}\right)\left(C_{\mathrm{f}}+\eta \rho\right)=\eta C_{\mathrm{f}} \\
\text { or } C_{\mathrm{f}}^{2}+C_{\mathrm{f}}(\eta \rho+\eta-C)-\eta \rho C=0
\end{gathered}
$$

only one solution of which is physically acceptable, that being

$$
C_{\mathrm{f}}=\frac{1}{2}\left\{C-\eta-\eta \rho+\left[(\eta+\eta \rho-C)^{2}+4 \eta \rho C\right]^{1 / 2}\right\} \quad[\mathrm{A}-9]
$$

The other solution would give $C_{\mathrm{f}}<0$. Thus, we have $C_{\mathrm{f}}>0$, and we can show from Eq. A-7 that $C_{\mathrm{f}}<C$, leading to the conclusion that $0<C_{\mathrm{a}}<C$, all of which are physically correct.

The corresponding relationship for $C_{\mathrm{a}}$ is easily obtained, i.e. 


$$
\begin{aligned}
C_{\mathrm{a}}= & C-C_{\mathrm{f}}=\frac{1}{2}\{C+\eta+\eta \rho \\
& \left.-\left[(\eta+\eta \rho-C)^{2}+4 \eta \rho C\right]^{1 / 2}\right\}
\end{aligned}
$$

The diffusion equation - The diffusion equation appropriate to this system is understandably more complex than the "usual" Fickian-type expression, due to the interchange of $\mathrm{Cr}^{\mathrm{VI}}$ between the free (diffusing) and bound (adsorbed) states. However, it can be derived based on a simple conservation-of-matter argument. Toward that end, consider again the slab of film extending from $x$ to $x+d x$, taking the surface area of the film to be $S$. Then

$$
\frac{\partial C}{\partial t}(x, t) S d x=\text { Rate at which } \mathrm{Cr}^{\mathrm{VI}} \text { is being added to the slab [A-11] }
$$

The only way this addition of matter can occur is by the diffusive flow of free $\mathrm{Cr}^{\mathrm{VI}}$, so that

$$
\frac{\partial C}{\partial t}(x, t) S d x=-D \frac{\partial C_{\mathrm{f}}}{\partial x}(x, t) S-\left[-D \frac{\partial C_{\mathrm{f}}}{\partial x}(x+d x, t) S\right] \quad \text { [A-12] }
$$

where $D$ is the diffusivity of the free $\mathrm{Cr}^{\mathrm{VI}}$. The first term on the right side of Eq. A-12 is the rate of influx of free $\mathrm{Cr}^{\mathrm{VI}}$ into the slab, and the second term is the rate of egress. Expanding that second term in a Taylor series and combining terms

$$
\frac{\partial C}{\partial t}=D \frac{\partial^{2} C_{\mathrm{f}}}{\partial x^{2}} \text { or } \frac{\partial C_{\mathrm{f}}}{\partial t}=D \frac{\partial^{2} C_{\mathrm{f}}}{\partial x^{2}}-\frac{\partial C_{\mathrm{a}}}{\partial t} \quad[\mathrm{~A}-13]
$$

dropping the $(x, t)$ arguments. The second form of Eq. A-13 is recognizable as Fickian diffusion in the presence of a sink. Dependence upon $C_{\mathrm{a}}$ in Eq. A-13 can be eliminated using Eq. A-7, which relates $C_{\mathrm{a}}$ to $C_{\mathrm{f}}$. We thus obtain

$$
\frac{\partial C_{\mathrm{f}}}{\partial t}\left[1+\frac{\eta^{2} \rho}{\left(C_{\mathrm{f}}+\eta \rho\right)^{2}}\right]=D \frac{\partial^{2} C_{\mathrm{f}}}{\partial x^{2}} \quad[\mathrm{~A}-14]
$$

Knowing $C_{\mathrm{f}}$ at a particular $x$ and $t$ also tells us the values of $C_{\mathrm{a}}$ and $C$ at that position and time via Eq. A-7.

Equation A-14 can be scaled, and in so doing, all explicit dependence on the parameters $\eta$ and $D$ is eliminated. Toward this end, we define the following dimension-less variables

$$
\xi \equiv \eta^{1 / 3} x, \quad \tau \equiv \eta^{2 / 3} D t, \quad \chi_{\mathrm{f}} \equiv \eta^{-1} C_{\mathrm{f}}
$$

in terms of which Eq. A-14 is reduced to

$$
\frac{\partial \chi_{\mathrm{f}}}{\partial \tau}\left[1+\frac{\rho}{\left(\chi_{\mathrm{f}}+\rho\right)^{2}}\right]=\frac{\partial^{2} \chi_{\mathrm{f}}}{\partial \xi^{2}}
$$

Some of our earlier results can also be scaled if we first define 


$$
\chi_{\mathrm{a}} \equiv \eta^{-1} C_{\mathrm{a}}, \quad \chi \equiv \eta^{-1} C
$$

in which case Eq. A-4, A-9, and A-10 become, respectively

$$
\begin{gathered}
\theta=\frac{k_{1} \chi_{\mathrm{f}}}{k_{1} \chi_{\mathrm{f}}+k_{2}} \text { or } \frac{k_{1} \chi_{\mathrm{f}}}{k_{2}}=\frac{\theta}{1-\theta} \\
\chi_{\mathrm{f}}=\frac{1}{2}\left\{\chi-1-\rho+\left[(1+\rho-\chi)^{2}+4 \rho \chi\right]^{1 / 2}\right\} \\
\chi_{\mathrm{a}}=\chi-\chi_{\mathrm{f}}=\frac{1}{2}\left\{\chi+1+\rho-\left[(1+\rho-\chi)^{2}+4 \rho \chi\right]^{1 / 2}\right\}
\end{gathered}
$$

Initial and boundary conditions.-The following initial conditions are imposed

$$
C(x, 0)=C_{0}, \quad C_{s}(0)=0 \quad[\mathrm{~A}-21]
$$

where $C_{\mathrm{s}}(t)$ is the concentration of $\mathrm{Cr}^{\mathrm{VI}}$ in the solution beyond the film, which occupies volume $V$. Moreover, it is assumed that $C_{\mathrm{f}}(x, 0)$ and $C_{\mathrm{a}}(x, 0)$ are related to $C(x, 0)$ through Eq. A-9 and A-10, respectively. The boundary conditions are as follows

$$
\frac{\partial C_{\mathrm{f}}}{\partial x}(0, t)=0, \quad C_{\mathrm{f}}(L, t)=C_{\mathrm{s}}(t)=-D \frac{S}{V} \int_{0}^{t} \frac{\partial C_{\mathrm{f}}}{\partial x}(L, t) d t \quad[\mathrm{~A}-22]
$$

The first of the two boundary conditions is a statement of the assumption that $\mathrm{Cr}^{\mathrm{VI}}$ does not diffuse backward, into the metal. The second is a statement of the fact that $C_{\mathrm{s}}(t)$ results from the diffusive flow of $\mathrm{Cr}^{\mathrm{VI}}$ from the film into the solution.

The boundary conditions can be scaled to make them consistent with Eq. A-16. Toward that end, we define the following new dimensionless parameters

$$
\chi_{\mathrm{s}} \equiv \eta^{-1} C_{\mathrm{s}}, \quad \sigma \equiv \eta^{2 / 3} S, \quad v \equiv \eta V, \quad \lambda \equiv \eta^{1 / 3} L \quad[\mathrm{~A}-23]
$$

Combining Eq. A-15 and A-23 with A-22, we find that the scaled boundary conditions are

$$
\frac{\partial \chi_{\mathrm{f}}}{\partial \xi}(0, \tau)=0, \quad \chi_{\mathrm{f}}(\lambda, \tau)=\chi_{\mathrm{s}}(\tau)=-\frac{\sigma}{v} \int_{0}^{\tau} \frac{\partial \chi_{\mathrm{f}}}{\partial \xi}(\lambda, \tau) d \tau \quad[\mathrm{A}-24]
$$

Note that there is no explicit dependence on $D$ or $\eta$ in Eq. A-24.

Global conservation of matter.-The diffusion equation is an expression of conservation of matter at the local or microscopic level. A global or macroscopic expression for the conservation of matter is 


$$
C_{\mathrm{o}} L=\int_{0}^{L} C(x, t) d x+\frac{V}{S} C_{\mathrm{s}}(t)
$$

This expression can also be presented in scaled form, first defining

$$
\chi_{\mathrm{o}} \equiv \eta^{-1} C_{\mathrm{o}}
$$

to obtain

$$
\chi_{0} \lambda=\int_{0}^{\lambda} \chi(\xi, \tau) d \xi+\frac{\nu}{\sigma} \chi_{\mathrm{s}}(\tau) \quad[\mathrm{A}-27]
$$

Rearranging Eq. A-27 and utilizing the second expression in Eq. A-24 yields

$$
\chi_{\mathrm{f}}(\lambda, \tau)=\frac{\sigma}{v}\left(\chi_{0} \lambda-\int_{0}^{\lambda}\left[\chi_{\mathrm{f}}(\xi, \tau)+\chi_{\mathrm{a}}(\xi, \tau)\right] d \xi\right) \quad[\mathrm{A}-28]
$$

But $\chi_{\mathrm{a}}{ }^{=} \chi_{\mathrm{f}} /(\chi \mathrm{f}+\rho)$, so differentiation with respect to $\tau$ yields

$$
\frac{\partial}{\partial \tau} \chi_{\mathrm{f}}(\lambda, \tau)=-\frac{\sigma}{v}\left[\int_{0}^{\lambda} \frac{\partial \chi_{\mathrm{f}}}{\partial \tau}(\xi, \tau)\left(1+\frac{\rho}{\left(\chi_{\mathrm{f}}(\xi, \tau)+\rho\right)^{2}}\right) d \xi\right] \quad \text { [A-29] }
$$

Numerical representation.-Equation A-16 represents a partial differential equation with boundary conditions expressed by the first expression in Eq. A-24 and by Eq. A-29. This partial differential equation can be reduced to a system of ordinary differential equations by discretizing the $\xi$ axis and assigning an ordinary differential equation to each of the points considered. To do this, divide the interval from 0 to $\lambda$ into $2 n$ equal subintervals. Then there will be $2 n+1$ nodes and $2 n+1$ ordinary differential equations. Let

$$
\Delta \xi=\frac{\lambda}{2 n} \quad[\mathrm{~A}-30]
$$

and

$$
\xi_{\mathrm{i}}=i \Delta \xi \text { for } i=0,1, \ldots, 2 n
$$

Let $\chi_{\mathrm{i}}, \chi_{\mathrm{f}, \mathrm{i}}$, and $\chi_{\mathrm{a}, \mathrm{i}}$ be the values of $\chi_{,}, \chi_{\mathrm{f}}$, and $\chi_{\mathrm{a}}$, respectively, at $\xi_{1}$, for $i=0,1, \ldots, 2 n$. The quantities $\chi_{\mathrm{i}}, \chi_{\mathrm{f}, \mathrm{i}}$, and $\chi_{\mathrm{a}, \mathrm{i}}$ are functions of $\tau$ alone. In terms of these new functions, the initial condition is

$$
\chi_{\mathrm{a}, \mathrm{i}}(0)+\chi_{\mathrm{f}, \mathrm{i}}(0)=\chi_{\mathrm{o}} \text { for } i=0,1, \ldots, 2 n-1 \quad[\mathrm{~A}-32]
$$




$$
\chi_{\mathrm{a}, 2 \mathrm{n}}(0)=\chi_{\mathrm{f}, 2 \mathrm{n}}(0)=0
$$

Given the value of $\chi_{0}$, the values of $\chi_{\mathrm{f}, \mathrm{i}}(0)$ can be obtained by applying Eq. A-19.

The value of $\partial^{2} \chi_{\mathrm{f}} / \partial \xi^{2}$ can be approximated by taking finite differences

$$
\frac{\partial^{2} \chi_{\mathrm{f}}(i \Delta \xi, \tau)}{\partial \xi^{2}}=\frac{\chi_{\mathrm{f}, \mathrm{i}-1}(\tau)-2 \chi_{\mathrm{f}, \mathrm{i}}(\tau)+\chi_{\mathrm{f}, \mathrm{i}+1}(\tau)}{(\Delta \xi)^{2}}+O\left[(\Delta \xi)^{3}\right] \quad[\mathrm{A}-34]
$$

where $O\left[(\Delta \xi)^{3}\right]$ is a term of order $(\Delta \xi)^{3}$. If that term is neglected, Eq. A-16 becomes

$$
\begin{aligned}
\frac{d \chi_{\mathrm{f}, \mathrm{i}}}{d \tau}= & {\left[1+\frac{\rho}{\left(\chi_{\mathrm{f}, \mathrm{i}}+\rho\right)^{2}}\right]^{-1} \frac{\chi_{\mathrm{f}, \mathrm{i}-1}-2 \chi_{\mathrm{f}, \mathrm{i}}+\chi_{\mathrm{f}, \mathrm{i}+1}}{(\Delta \xi)^{2}} } \\
& \text { for } 0<i<2 n
\end{aligned}
$$

For the boundary at $\xi=0$, Eq. A-35 is slightly simplified. To accommodate Eq. A-24, one may define a fictitious $\chi_{\mathrm{f},-}$ ${ }_{1}=\chi_{\mathrm{f}, 1}$. Then Eq. A-35 becomes

$$
\frac{d \chi_{\mathrm{f}, 0}}{d \tau}=\left[1+\frac{\rho}{\left(\chi_{\mathrm{f}, 0}+\rho\right)^{2}}\right]^{-1} \frac{2 \chi_{\mathrm{f}, 1}-2 \chi_{\mathrm{f}, 0}}{(\Delta \xi)^{2}} \quad[\mathrm{~A}-36]
$$

The most difficult part of the problem is implementing the boundary condition given by Eq. A-29. As a first step toward this, define $s_{\mathrm{i}}$ such that

$$
\begin{gathered}
s_{0}=s_{2 \mathrm{n}}=1 \\
s_{\mathrm{i}}=4 \text { for } i=1,3, \ldots, 2 n-1 \\
s_{\mathrm{i}}=2 \text { for } i=2,4, \ldots, 2 n-2 \\
\text { [A-38] }
\end{gathered}
$$

Then for any function $f$, Simpson's rule may be implemented as

$$
\int_{0}^{\lambda} f d \xi=\frac{\Delta \xi}{3} \sum_{\mathrm{i}=0}^{2 \mathrm{n}} s_{\mathrm{i}} f_{\mathrm{i}}+O\left[(\Delta \xi)^{4}\right] \quad[\mathrm{A}-40]
$$

where $O\left[(\Delta \xi)^{4}\right]$ is a term of order $(\Delta \xi)^{4} \cdot{ }^{17}$ If the higher-order term in Eq. A-40 is neglected, Eq. A-29 becomes, in discretized form

$$
\frac{d \chi_{\mathrm{f}, 2 \mathrm{n}}}{d \tau}=-\frac{\sigma \Delta \xi}{3 v} \sum_{\mathrm{i}=0}^{2 \mathrm{n}} s_{\mathrm{i}} \frac{d \chi_{\mathrm{f}, \mathrm{i}}}{d \tau}\left[1+\frac{\rho}{\left(\chi_{\mathrm{f}, \mathrm{i}}+\rho\right)^{2}}\right] \quad[\mathrm{A}-41]
$$


Note that $d \chi_{\mathrm{f}, 2 \mathrm{n}} / d \tau$ appears on both sides of Eq. A-41. If Eq. A-41 is solved for $d \chi_{\mathrm{f}, 2 \mathrm{n}} / d \tau$, one obtains

$$
\begin{aligned}
\frac{d \chi_{\mathrm{f}, 2 \mathrm{n}}}{d \tau}= & -\frac{\frac{\sigma \Delta \xi}{3 v}}{1+\frac{\sigma \Delta \xi}{3 v}\left[\frac{\rho}{\left(\chi_{\mathrm{f}, 2 \mathrm{n}}+\rho\right)^{2}}\right]} \\
& \times \sum_{\mathrm{i}=0}^{2 \mathrm{n}-1} s_{\mathrm{i}} \frac{d \chi_{\mathrm{f}, \mathrm{i}}}{d \tau}\left[1+\frac{\rho}{\left(\chi_{\mathrm{f}, \mathrm{i}}+\rho\right)^{2}}\right]
\end{aligned}
$$

Equations A-35, A-36, and A-42 provide a set of ordinary differential equations that may be solved to provide a discretized approximation to $\chi_{\mathrm{f}}(\xi, \tau)$.

A MathCAD program was written to solve these equations and to plot the predicted solution concentration of $\mathrm{Cr}^{\mathrm{VI}}$ as a function of time. Fittings to the data have been made by changing the values of parameters $D, L, \rho$, and $\eta$.

Asymptotic behavior $(t \rightarrow \infty)$.- The concentration of $\mathrm{Cr}^{\mathrm{VI}}$ in the solution at asymptotically large times can be computed by equating its concentration in the film at $t=0$ to that in the film plus that in the solution at $t \rightarrow \infty$. Thus,

$$
C_{\mathrm{o}} S L=C(x, \infty) S L+C_{\mathrm{s}}(\infty) V \quad[\mathrm{~A}-43]
$$

Note that $C$ must become independent of $x$ as equilibrium is approached. In addition

$$
C(x, \infty)=C_{\mathrm{f}}(x, \infty)+C_{\mathrm{a}}(x, \infty)
$$

and

$$
C_{\mathrm{f}}(x, \infty)=C_{\mathrm{s}}(\infty)
$$

from which we obtain

$$
\begin{aligned}
C_{\mathrm{o}} S L & =\left[C_{\mathrm{f}}(x, \infty)+C_{\mathrm{a}}(x, \infty)\right] S L+C_{\mathrm{s}}(\infty) V \\
& =C_{\mathrm{s}}(\infty)(V+S L)+C_{\mathrm{a}}(x, \infty) S L
\end{aligned}
$$

We can eliminate $C_{\mathrm{a}}$ using Eq. A-7

$$
C_{\mathrm{a}}(x, \infty)=\frac{\eta C_{\mathrm{f}}(x, \infty)}{C_{\mathrm{f}}(x, \infty)+\eta \rho}
$$

Combining Eq. A-45 through A-47 


$$
C_{\mathrm{o}} S L=C_{\mathrm{s}}(\infty)(V+S L)+\frac{\eta C_{\mathrm{s}}(\infty)}{C_{\mathrm{s}}(\infty)+\eta \rho} S L
$$

Dividing through by $S L$ and defining a $=V / S L$

$$
C_{\mathrm{o}}=C_{\mathrm{s}}(\infty)(\sigma+1)+\frac{\eta C_{\mathrm{s}}(\infty)}{C_{\mathrm{s}}(\infty)+\eta \rho} \quad[\mathrm{A}-49]
$$

Equation A-49 can be expressed as a quadratic expression in $C_{\mathrm{s}}(\infty)$, i.e.

$$
C_{\mathrm{o}}\left[C_{\mathrm{s}}(\infty)+\eta \rho\right]=C_{\mathrm{s}}(\infty)(\sigma+1)\left[C_{\mathrm{s}}(\infty)+\eta \rho\right]+\eta C_{\mathrm{s}}(\infty) \quad[\mathrm{A}-50]
$$

Putting Eq. A-50 into standard quadratic form

$$
(\sigma+1) C_{\mathrm{s}}(\infty)^{2}+\left[(\sigma+1) \eta \rho+\eta-C_{\mathrm{o}}\right] C_{\mathrm{s}}(\infty)-C_{\mathrm{o}} \eta \rho=0 \quad[\mathrm{~A}-51]
$$

Equation A-51 has two roots, only one of which is physically acceptable, the other being negative.

\section{References}

1. F. Hunkeler and H. Bohni, Corrosion (Houston), 37, 645 (1981).

2. H. Bohni and H. H. Uhlig, J. Electrochem. Soc., 116, 906 (1969).

3. J. Zhao, G. Frankel, and R. L. McCreery, J. Electrochem. Soc., 145, 2258 (1998).

4. L. Xia, E. Akiyama, G. Frankel, and R. McCreery, J. Electrochem. Soc., 147, 2556 (2000).

5. F. W. Lytle, R. B. Greegor, G. L. Bibbins, K. Y. Blohowiak, R. E. Smith, and G. D. Tuss, Corros. Sci., 37, 349 (1995).

6. V. G. Poulopoulou, E. Vrachnou, S. Koinis, and D. Katakis, Polyhedron, 16, 521 (1997).

7. J. J. Cruywagen, J. B. B. Heyns, and E. A. Rohwer, Polyhedron, 17, 1741 (1998).

8. L. Xia and R. L. McCreery, J. Electrochem. Soc., 146, 3696 (1999).

9. W. McGovern, P. Schmutz, R. G. Buchheit, and R. L. McCreery, J. Electrochem. Soc., 147, 4494 (2000).

10. H. Stunzi and W. Marty, Inorg. Chem., 22, 2145 (1983).

11. V. Laget, C. S. Jeffcoate, H. S. Isaacs, and R. G. Buchheit, J. Electrochem. Soc., Submitted.

12. M. Morita, M. L. Longmire, and R. W. Murray, Anal. Chem., 60, 2770 (1988).

13. T. Ikeda, R. Schmehl, P. Denisevich, K. Willman, and R. W. Murray, J. Am. Chem. Soc., 104, 2683 (1982).

14. F. M. Gray, Solid Polymer Electrolytes: Fundamentals and Technological Applications, VCH Publishers,Inc.,New York (1991).

15. C. S. Jeffcoate, H. S. Isaacs, A. J. Aldykiewicz, Jr., and M. P. Ryan, J. Electrochem. Soc., 147, 540 (2000).

16. L. Xia and R. L. McCreery, J. Electrochem. Soc., 145, 3083 (1998).

17. G. Dahlquist and A. Bjorck, Numerical Methods, pp. 267, 273, Prentice-Hall Englewood Cliffs, NJ (1974). 